\title{
Correction to: Enhanced Endoscopy in Bladder Cancer
}

\author{
Shane Pearce ${ }^{1} \cdot$ Siamak Daneshmand ${ }^{1}$
}

Published online: 5 April 2019

(C) Springer Science+Business Media, LLC, part of Springer Nature 2019

\section{Correction to: Current Urology Reports (2018) 19:84 https://doi.org/10.1007/s11934-018-0833-9}

Author Siamak Daneshmand would like to note that this article published in Current Urology Reports inadvertently did not disclose financial information that could possibly be a conflict of interest.

Dr. Siamak Daneshmand is a paid consultant for Photocure.

Publisher's Note Springer Nature remains neutral with regard to jurisdictional claims in published maps and institutional affiliations.

The online version of the original article can be found at https://doi.org/ 10.1007/s11934-018-0833-9

\footnotetext{
Shane Pearce

shane.pearce@med.usc.edu

Siamak Daneshmand

daneshma@med.usc.edu

1 Institute of Urology, USC Keck/Norris Comprehensive Cancer

Center, University of Southern California, 1441 Eastlake Ave, Suite 7416, Los Angeles, CA 90089, USA
} 